\title{
Age-related maculopathy: its genetic basis
}

Age-related maculopathy (ARM) is the presentday name for a disorder that in the past had many names in ophthalmology, among others senile macular degeneration and disciform macular degeneration. Age-related macular degeneration was coined senile macular degeneration in 1885 by Haab, ${ }^{1}$ about 100 years after Buzzi from Milan published this paper on the existence of the macula lutea. In 1875 Hutchinson and $\mathrm{Tay}^{2}$ named probably the same disorder central chorioretinal disease. The international classification system of ARM was the first attempt to systematically classify the ageing changes in the retina, associated with drusen larger than small, hard ones with a

P.T.V.M. de Jong A.A.B. Bergen J.M. Assink Department Ophthalmogenetics The Netherlands Ophthalmic Research Institute Amsterdam The Netherlands

P.T.V.M. de Jong C.C.W. Klaver C.M. van Duijn J.M. Assink Department of Epidemiology and Biostatistics Erasmus University Rotterdam, The Netherlands

P.T.V.M. de Jong Department of Ophthalmology Academic Medical Centre Amsterdam, The Netherlands

C.C.W. Klaver

J.M. Assink

Department of

Ophthalmology

University Hospital

Rotterdam

Rotterdam, The Netherlands

P.T.V.M. de Jong

Meibergdreef 47

1105BA Amsterdam

The Netherlands

e-mail:

P.deJong@ioi.knaw.nl diameter $\leqslant 65 \mu \mathrm{m}$, as ARM. ${ }^{3}$ This system was based on the presence of various fundus abnormalities associated with ageing in which it was assumed that they form an ascending order of probability to lead to one of the two endstages of ARM. Indeed from a follow-up study on ARM it seems that there is a more or less constant progression over 2 years in which onequarter of cases with ARM go on to a higher stage (C.C.W. Klaver, unpublished; see Table 1).

The hallmark of ARM is the presence of drusen, although this may vary from person to person. There may also be racial variations as Japanese subjects seem to have fewer drusen associated with ARM than do Caucasians. Drusen are of course characteristic of ARM but not exclusive to this disorder. In general terms they reflect dysfunction of the retinal pigment epithelium (RPE). This may occur apart from ARM, e.g. above a naevus of the choroid, in several hereditary eye disorders and in kidney diseases. In the kidney glomerulus similar deposits are found (M. Tso, personal communication 2001). Drusen are most probably constituted of basal membrane degradation products and Gass thought that they are only one common end product of RPE failure. ${ }^{4}$ Several studies by Hageman have shown in the meantime that a large variety of drusen exists. Clear evidence for the genetic basis of drusen came from one study in which a significantly higher correlation of the number and density of drusen was found in 53 sib pairs compared with 50 spouse pairs. ${ }^{5}$
PAULUS T.V.M. DE JONG, ARTHUR A.B. BERGEN, CAROLINE C.W. KLAVER, CORNELIA M. VAN DUIJN, JACQUELINE M. ASSINK

The end-stages of ARM are dry (geographic atrophy) and wet (neovascular or disciform) macular degeneration and are called age-related macular degeneration (AMD). ${ }^{3}$ Thus ARM and AMD are essentially diagnosed by exclusion of other disorders mimicking drusen, pigmentary changes, geographic atrophy and a disciform reaction.

Only about 100 years after Haab's publication it was seriously considered that there might be a genetic component to AMD. We will give a short historical overview of the evidence for the genetic influence on ARM and next will discuss various approaches to the study of the genetics of ARM, starting from the ophthalmologist's point of view.

\section{Evidence for heredity of ARM}

\section{Twin studies}

Twin studies often given the first indication of a disorder being genetic, and the first twin report on AMD known to us was in $1985 .{ }^{6}$ After two more case reports, ${ }^{7,8}$ a study in 9 monozygotic twin pairs showed concordance in AMD type in 8 of them. ${ }^{9}$ In a larger twin study about onequarter had ARM. ${ }^{10}$ All 25 homozygotic twin pairs who had ARM were afflicted to a similar degree, while this held for only $42 \%$ of the dizygotic pairs. ${ }^{10}$ The number of monozygotic twins was about 2.5 times higher than the dizygotic ones. As in all the following studies $^{11,12}$ caution is needed in interpreting these results. Apart from selection bias, the use of different grading systems for ARM (especially when no fundus pictures are taken) is often a source of misinterpretation of the results. This holds even more for studies using history data, as we will see in the next paragraph. Nevertheless, twin studies clearly point to a genetic factor in ARM.

\section{Family studies}

Familial occurrence of ARM was first described in $1875 .^{2}$ About 100 years later several more reports of ARM in families appeared. ${ }^{4,13-15}$ In a recent study of a family with 10 affected members a locus for AMD was found on 
Table 1. Stratification of ARM in exclusive stages of ascending risk of developing AMD

\begin{tabular}{lll}
\hline Stage of ARM & Stage of ARM & Criteria \\
\hline No ARM & & No ARM features or only drusen $\leqslant 63 \mu \mathrm{m}$ \\
Early ARM & Stage 1 (a) & Soft distinct drusen only \\
& (b) & Pigmentary irregularities only \\
& Stage 2 (a) & Soft indistinct drusen or reticular drusen \\
& (b) & Soft distinct drusen with pigmentary irregularities \\
Late ARM, equal to AMD & Stage 4 & Soft indistinct or reticular drusen with pigmentary irregularities \\
& & Dry (= atrophic = geographic atrophy) or wet (= neovascular = disciform) AMD \\
\hline
\end{tabular}

chromosome $1 \mathrm{q} 25-31 .^{16}$ This seems to be at present one of the best pieces of evidence for the heredity of AMD. Several more families with ARM were described in which a wide spectrum of fundus features of ARM was found within a single family. ${ }^{17}$ Recently we identified a large family with 9 members with ARM and 13 with AMD in a genetically isolated population. ${ }^{18}$ Thus family studies also provide evidence for a genetic component in ARM.

\section{Clinical association studies}

The first study to compare data on the history of AMD in relatives of affected subjects and those of a control population was published in $1983 .{ }^{19}$ A positive family history was found in $21.6 \%$ of affected subjects versus $8.6 \%$ of controls. The value of this study was that it was the first of its kind; later, however, the feeling that history data are less reliable was substantiated. ${ }^{20}$ Recently another study found an increased risk of ARM related to a positive family history. ${ }^{21}$ The flaw in using family history data without checking them is probably also the reason why in two clinic-based studies the familial risk of ARM varied from $19.3^{22}$ to $2.4 .^{23}$ The first study ${ }^{22}$ compared first degree relatives of 36 patients with AMD with those of 36 patients having a cataract extraction. In the second study ${ }^{23}$ records of first degree relatives of 119 cases with early or late ARM were compared with those of 72 control subjects. The discrepancy in odds ratios between these two studies may be explained by differences in the examination and classification methods, by the use of non-verified data on family history, self-reported diagnoses and data from nonstandardized medical charts, as well as by possible bias due to the fact that the studies were clinic-based rather than population-based.

\section{Population-based case-control study}

One learns from those leading the way and thus we designed a study to overcome some of the pitfalls mentioned in the previous section. ${ }^{24}$ All first degree relatives of 87 participating (response rate $86.1 \%$ ) patients with AMD from the population-based Rotterdam Study were compared with all first degree relatives of 135 participating (response rate $87.7 \%$ ) control subjects from the same population. In the sibs and children of these people the participation rates varied between $80 \%$ and $88 \% .{ }^{24}$ All participating subjects were examined using the same standardized examination protocol of the Rotterdam Study, ${ }^{24}$ including grading on fundus colour transparencies according to the International Classification System. ${ }^{3}$ Thus the odds ratio for early ARM (Table 1) in first degree family members of ARM cases was found to be 4.8 (95\% confidence interval (CI) 1.8-12.2) and for AMD 19.8 (95\% CI 3.1-126). The life-time risk for AMD was estimated to be $50 \%$ (95\% CI 26-73) for relatives of cases versus $12 \%$ (95\% CI $2-16)$ for those of controls, a risk ratio of 4.2. The population risk attributable to genetic factors was calculated to be $23 \%{ }^{24}$ Together with the risk factors that became known in the meantime from epidemiological studies, smoking being a major and consistent one, this means that ARM is most probably a multifactorial disorder. In a later study this overall risk for relatives of AMD cases was differentiated and found to vary remarkably among families of subjects having AMD. ${ }^{25}$ About $70 \%$ of those families had no increased risk and at the other end of the distribution a few per cent of the families had odds ratios for developing AMD of up to 30 , with quite wide confidence intervals. ${ }^{25}$ At present we are trying to fine-tune these findings by adjusting for the size of the families.

\section{Racial studies}

Most early reports on racial differences in the prevalence of ARM indicated a higher prevalence in Caucasians. ${ }^{26,27}$ As those studies did not examine a large number of Caucasians at the same time in the same geographic area, one never can be sure whether the differences really were racial or environmental. Similarly, the notion that the prevalence of ARM is rising steeply in Japan cannot be substantiated as long as there are no good baseline data available. However, of late several new studies ${ }^{28-31}$ that overcame these problems showed that there are racial differences in ARM, if only in terms of varying expression in different age strata. Thus blacks seem to have early ARM at an earlier age than Caucasians ${ }^{30}$ but a lower prevalence of AMD. ${ }^{28}$

There are also racial differences in refraction: for example, myopia is more common in Asian than in Caucasian populations. Myopia is in itself a multifactorial and complex anomaly of refraction. Nevertheless it is intriguing why hypermetropia seems to be associated with $\mathrm{ARM}^{32}$ although this did not reach significance in a few studies ${ }^{33,34}$ or even was protective in others. ${ }^{35}$ Also from our clinical impression ARM, and especially early ARM with many or confluent drusen, is rarer in myopic eyes. We might hypothesise that this is 
due to a thinner retinal pigment epithelium, choriocapillaris, choroid, sclera (or all four of them) in myopic eyes compared with hypermetropic eyes. Less disciform AMD in myopic eyes might partly be due to confounding because one would be inclined not to classify these as AMD according to the International Classification System ${ }^{3}$ but as a Fuchs' spot or disciform reaction due to myopia.

\section{Genetic analytical methods for studying ARM}

Apart from the type of studies mentioned above, to which we will refer in the following sections, we would like to mention a few different approaches to genetic studies depending on what kind of patient material one has. A clinician studying genetics of ARM may have at her or his disposal isolated patients with ARM, single sib pairs, extended sib pairs with three to five sibs, monozygotic or dizygotic twins, multigeneration families, clinic-based groups of isolated cases and controls, and similar cases and controls derived from general or genetically isolated populations. Depending on the available patient material there are often several options for studying the genetics of ARM. In each approach one often also has to make assumptions about the mode of inheritance or about ARM being a monogenic, oligogenic or complex disorder. Usually one has to carry out multiple analyses for different hypotheses about the mode of inheritance. If this mode is unknown we will see below that one can perform a segregation analysis to see what models best fit the available data. Given the late expression of ARM it will be hard to find large multigeneration families with this disorder and thus most studies have looked at unrelated cases and controls, mostly from clinics. In such a case-control setting association studies using a candidate gene approach are indicated. If one nevertheless has at one's disposal one or more multigeneration families segregating ARM, linkage analysis is indicated followed by positional cloning of the disease gene. One should be aware, however, that ARM seems to be only partly genetically determined, multifactorial, and not a monogenic disorder. This will complicate linkage analysis. In the following sections we will mention some of the studies on ARM performed so far.

\section{Segregation analysis}

'Segregation' in general terms means separation, but in genetics it is used in a special way: segregation analysis statistically tests genetic models on available data. In essence one examines various models for the best fit. In the first segregation analysis on AMD in the Beaver Dam Eye Study four models - three of dominant Mendelian inheritance and one general model - were used. ${ }^{36}$ The authors came to the conclusion that their data on 546 sibships best fitted an autosomal dominant inheritance model in which a single major gene could explain between $59 \%$ and $62 \%$ of the variability in ARM. A major random environmental factor was improbable. The number of genes involved could not be predicted. ${ }^{36}$ We think at present, given the locus found on chromosome $1 q^{16}$ the small number of ABCR mutations found in $\mathrm{ARM}^{37}$ and our own data, that it is hardly probable this model $^{36}$ still holds.

\section{Association studies}

In genetic association studies one compares unrelated cases with a disorder with unrelated controls, from either a clinic or a general population, in order to test the contribution of genetic factors in known candidate genes to a disease. General population means here also not derived from a genetic isolate. One assumes that the variables in the population leading to the associations are dependent on each other, leading to a so-called nonparametric test. Association studies are often performed in multifactorial disorders. In order to perform an association study one mostly needs large numbers of well-defined cases and controls. Because AMD is a diagnosis by exclusion of other disorders, such as disciform macular degeneration due to myopia, trauma or inflammation, there is always a danger of confounders such as mixing similar phenotypes with different genotypes. This could be one of the reasons for the controversy that arose around the role in AMD of mutations in the $A B C R$ gene, known to be involved in Stargardt's disease. ${ }^{14,37-41}$ It is beyond the scope of this review to go into much detail here. In essence the general feeling at present seems to be that, due to the classification of ARM in the cases, the method of selecting controls, selective pooling of alleles and the statistics used, the role of $A B C R$ in AMD is much smaller than originally assumed. ${ }^{37}$ In this last publication, finally, only two $A B C R$ mutations were tested. It is to be expected that in the near future more clarity will be obtained in this matter.

As apolipoprotein $\mathrm{E}$ (apoE) polymorphism plays a role in Alzheimer's disease, the $\epsilon 4$ allele leading to an increased risk, we hypothesised that it would also lead to increased ARM. In an associated study between 88 AMD cases and 901 controls from the population of the Rotterdam Study, we found an inverse association. Subjects with the apo $\epsilon 4$ allele had a decreased risk of AMD with an odds ratio of 0.43 (95\% CI $0.21-0.88)$ and the risk in those with the $\epsilon 2$ allele was increased (OR 1.5; 95\% CI 0.8-2.8). ${ }^{42}$

\section{Allele sharing studies}

Allele sharing methods are mostly used in related cases, i.e. sib pairs or large families with a multifactorial disease, or in genetically isolated populations. In these populations mostly a combination of linkage analysis and association study is used. So far no ARM study on a large number of sib pairs has appeared. This is probably due partly to the limited number of sib pairs one may find in such an age-related disorder and to the difficulty of the sib pair approach in a multifactorial disorder. Thus 
for a successful sib pair study we would estimate that one needs 500 to $1000 \mathrm{sib}$ pairs that, of course, would have to be well documented.

\section{Studies using linkage analysis}

Linkage analysis is mostly used in families with a clear inheritance pattern, although this latter may be also only assumed. Finding large families with more than 10-15 affected members is hampered by the late onset of the disease, leading to a paucity of surviving parents and uncertainty about the genetic status of the children. One large family published so far led to a locus on chromosome 1q25-31. ${ }^{16}$ In another family no mutation in the TIMP-3 gene (responsible for Sorsby's fundus dystrophy $)^{43}$ was detected. Nor could mutations in the $A B C R$ gene be found in 38 ARM families. ${ }^{15}$ In the family we have studied, so far no known mutations of candidate genes have been encountered, also suggesting that ARM is a multifactorial disorder. ${ }^{18}$

\section{Candidate gene approach}

Mention should be made of the candidate gene approach and new methods of identifying retina (ARM)-specific genes.

We have seen that candidate gene approaches have been widely used in association with positional cloning studies. So far this approach has been of limited value in finding genes for ARM, perhaps because most candidate genes have been related to monogenic disorders and ARM most likely is a multifactorial disease. One can find nearly every month new candidate genes on several databases on the internet, ${ }^{44}$ among others on http:/ / www.sph.uth.tmc.edu/retnet, and in addition more and more genes from other species become available. Given the speed with which new data on the human genome are becoming available, it is to be hoped that the candidate gene approach may contribute more to the ARM genetic solution.

There are several new methods of finding retinaspecific genes, such as differential hybridisation, cDNA library subtraction and clone sequencing, and computerassisted collection of expressed sequence tags (ESTs). By checking ESTs preferentially expressed in the human retina one can try to find new candidate genes for AMD. ${ }^{45}$ The majority of the genes involved in singlegene retinal disorders are expressed only in the eye. There is a redundancy of ESTs and by testing the in vitro expression profile of ESTs from eye cDNA libraries 39 genes with specific transcription in the human retina were found. ${ }^{45}$ This seems to be a very promising tool for finding new genes that might also be involved with ARM. Finally, multi-array systems for specific analysis of up- or down-regulated genes in the ageing retina and in the retina affected by ARM become more and more suitable for research in ARM, so that we expect that in the coming years genetic research in ARM will advance at a dazzling speed compared with the past 200 years.
Once genes for ARM have been found, functional studies on them will have to prove the genetic basis for ARM. It might be a problem, however, to find a suitable animal to study the phenotype. So far it is uncertain whether one could elicit ARM, or even more AMD, in, for example, mice, which have no fovea. The future will have to tell us whether the zebra fish will be a good model for ARM.

\section{Conclusions}

There is sufficient evidence that ARM is a partly genetically determined, multifactorial disorder. The best pieces of evidence so far are the locus on chromosome 1q and the two $A B C R$ gene mutations described. The candidate gene approach to ARM is hampered by ARM being a multifactorial disorder. However, the availability of the human genome sequence will enhance the possible use of candidate genes. It is further to be expected that complementary techniques such as the use of microarrays, comparative gene mapping in different species, and in silico cloning (obtaining computer data from large gene bases) will speed up the search for ARM genes.

\section{References}

1. Haab O. Erkrankungen der Macula lutea. Centralbl prakt Augenheilk 1885;9:383-4.

2. Hutchinson J, Tay W. Symmetrical central chorio-retinal disease in senile persons. R Lond Ophthalmic Hosp Rep 1875;8:231-44.

3. The International Age-Related Maculopathy Study Group. An international classification and grading system for ARM. Surv Ophthalmol 1995;39:367-74

4. Gass JDM. Drusen and disciform macular detachment and degeneration. Arch Ophthalmol 1973;90:206-17.

5. Piguet B, Wells JA, Palmvang IB, Wormald R, Chisholm IH, Bird AC. Age-related Bruch's membrane change: a clinical study of the relative role of heredity and environment. $\mathrm{Br} \mathrm{J}$ Ophthalmol 1993;77:400-3.

6. Melrose MA, Magargal LE, Lucier AC. Identical twins with subretinal neovascularization complicating senile macular degeneration. Ophthalmic Surg 1985;16:648-51.

7. Doss AA, Bovet J. Monozygotic twin brothers with agerelated macular degeneration. Ophthalmologica 1992;205:24-8.

8. Meyers SM, Zachary AA. Monozygotic twins with agerelated macular degeneration. Arch Ophthalmol 1988;106:651-3.

9. Klein ML, Mauldin WM, Stoumbos VD. Heredity and agerelated macular degeneration: observations in monozygotic twins. Arch Ophthalmol 1994;112:932-7.

10. Meyers SM, Greene T, Gutman FA. A twin study of agerelated macular degeneration. Am J Ophthalmol 1995;120:757-66.

11. Grizzard WS, Beck RW. Twin study of age related macular degeneration. Invest Ophthalmol Vis Sci 1994;35:1504.

12. Gottfredsdottir MS, Sverisson T, Musch DC, Stefansson E. Age-related macular degeneration in monozygotic twins and their spouses in Iceland. Acta Ophthalmol Scand 1999;77:422-5.

13. Francois J. The differential diagnosis of tapetoretinal degenerations. Arch Ophthalmol 1958;59:88-120.

14. Bradley AE. Dystrophy of the macula. Am J Ophthalmol 1966;61:1-24. 
15. de la Paz MA, Abau-Donia $\mathrm{S}$, Heinis, $\mathrm{R}$, et al. Analysis of the Stargardt disease gene $(A B C R)$ in age-related macular degeneration. Ophthalmology 1999;106:1531-6.

16. Klein ML, Schultz DW, Edwards A, et al. Age-related macular degeneration: clinical features in a large family and linkage to chromosome 1q. Arch Ophthalmol 1998;116:1082-8.

17. De la Paz MA, Pericak-Vance MA, Haines JL, Seddon JM. Phenotypic heterogeneity in families with age-related macular degeneration. Am J Ophthalmol 1997;124:331-43.

18. Assink JJM. Age-related maculopathy: a genetic and epidemiologic approach. PhD thesis. Rotterdam: Print Partners Ipskamp.

19. Hyman LG, Lilienfeld AM, Ferris FL, et al. Senile macular degeneration: a case control study. Am J Epidemiol 1983;118:213-27.

20. Linton KL, Klein BE, Klein R. The validity of self-reported and surrogate-reported cataract and age-related macular degeneration in the Beaver Dam Eye Study. Am J Epidemiol 1991;134:1438-46.

21. Smith W, Mitchell P. Family history and age-related maculopathy: the Blue Mountains Eye Study. Aust N Z J Ophthalmol 1998;26:203-6.

22. Silvestri G, Johnston PB, Hughes AE. Is genetic predisposition an important risk factor in age-related macular degeneration? Eye 1994;8:564-8.

23. Seddon JM, Ajani UA, Mitchell BD. Familial aggregation of age-related maculopathy. Am J Ophthalmol 1997;123:199-206

24. Klaver CCW, Wolfs RCW, Assink JJM, van Duijn CM, Hofman A, de Jong PTVM. Genetic risk of age-related maculopathy: population-based familial aggregation study. Arch Ophthalmol 1998;116:1646-51.

25. Klaver CCW. Genetic epidemiologic studies on age-related maculopathy: a population based approach. PhD thesis. Rotterdam: Print Partners Ipskamp.

26. Gregor Z, Joffe L. Senile macular changes in the black African. Br J Ophthalmol 1978;62:547-50.

27. Taylor HR. Prevalence and causes of blindness in Australian Aborigines. Med J Aust 1980;1:71-6.

28. Sommer A, Tielsch JM, Katz J. Racial differences in the causespecific prevalence of blindness in east Baltimore. N Engl J Med 1991;325:1412-7.

29. Schachat AP, Hyman L, Leske MC, et al. Features of agerelated macular degeneration in a black population. Arch Ophthalmol 1995;113:728-35.

30. Klein R, Rowland MC, Harris MI. Racial/ethnic differences in age-related maculopathy. Ophthalmology 1995;102:371-81.
31. Cruickshanks KJ, Hamman RF, Klein R, et al. The prevalence of age-related maculopathy by geographic region and ethnicity: the Colorado-Wisconsin Study of age-related maculopathy. Arch Ophthalmol 1997;115:242-50.

32. The Eye Disease Case-Control Study Group. Risk factors for neovascular age-related macular degeneration. Arch Ophthalmol 1992;110:1701-8.

33. Blumenkranz MS, Russell SR, Robey MG, et al. Risk factors in age-related maculopathy complicated by choroidal neovascularization. Ophthalmology 1986;93:552-8.

34. Vingerling JR, Hofman A, Grobbee DE, de Jong PTVM. Agerelated macular degeneration and smoking: the Rotterdam Study. Arch Ophthalmol 1996;114:1193-6.

35. Klein R, Klein BEK, Franke T. The relationship of cardiovascular disease and its risk factors to age-related maculopathy. Ophthalmology 1993;100:404-14.

36. Heiba IM, Elston RC, Klein BEK, et al. Sibling correlations and segregation analysis of age-related maculopathy: the Beaver Dam Eye Study. Genet Epidemiol 1994;11:51-67.

37. Allikmets R, Shroyer NF, Singh N, Seddon JM, Lewis RA, Bernstein PS, et al. Mutation of the Stargardt disease gene $(A B C R)$ in age-related macular degeneration. Science 1997;277:1805-7.

38. Dryja TP, Briggs CE, Berson EL, et al. $A B C R$ gene and agerelated macular degeneration [letter]. Science Online 1998;279:1107.

39. Klaver CCW, Assink JJM, Bergen AAB, et al. ABCR gene and age-related macular degeneration [letter]. Science Online 1998;279:1107.

40. Stone EM, Webster AR, Vandenburgh K, et al. Allelic variation in $A B C R$ associated with Stargardt but not with age-related macular degeneration. Nature Genet 1998;20:328-9.

41. Allikmets R. The International ABCR Screening Consortium: further evidence for an association of $A B C R$ alleles with agerelated macular degeneration. Am J Human Genet 2000;67:487-91.

42. Klaver CCW, Kliffen M, van Duijn CM, Hofman A, Cruts M, Grobbee DE, et al. Genetic association of apolipoprotein E with age-related macular degeneration. Am J Hum Genet 1998;63:200-6.

43. De la Paz MA, Pericak V, Lennon F, Haines JL, Seddon JM. Exclusion of TIMP3 as a candidate locus in age-related macular degeneration. Invest Ophthalmol Vis Sci 1997;38:1060-5.

44. Evans JR. Risk factors for age-related macular degeneration. Progr Ret Eye Res 2001;20:227-53.

45. Stöhr H, Mah N, Schulz HL, Gehring A, Fröhlich S, Weber BHF. EST mining of the UniGene dataset to identify retinaspecific genes. Cytogenet Cell Genet 2000;91:267-77. 